Research Article

\title{
Pharmacokinetic and Lipidomic Assessment of the In Vivo Effects of Parishin A-Isorhynchophylline in Rat Migraine Models
}

\author{
Chaoqun Zhou, ${ }^{1}$ Mingzhen He, ${ }^{1,2}$ Chunyan Peng, ${ }^{1}$ Jianjun Yu, ${ }^{1}$ Zhifeng Li, ${ }^{1,2}$ Maofu Zhou, ${ }^{1}$ \\ Yan Li, ${ }^{1}$ Shilin Yang, ${ }^{2}$ Hui Ouyang $\mathbb{D}^{1}$, and Yulin Feng ${ }^{1,2}$ \\ ${ }^{1}$ Jiangxi University of Traditional Chinese Medicine, Nanchang, China \\ ${ }^{2}$ State Key Laboratory of Innovative Drug and Efficient Energy-Saving Pharmaceutical Equipment, Nanchang, China \\ Correspondence should be addressed to Hui Ouyang; huiouyang@163.com
}

Received 18 December 2019; Accepted 27 March 2020; Published 6 July 2020

Academic Editor: Mohamed Abdel-Rehim

Copyright ( $\odot 2020$ Chaoqun Zhou et al. This is an open access article distributed under the Creative Commons Attribution License, which permits unrestricted use, distribution, and reproduction in any medium, provided the original work is properly cited.

\begin{abstract}
Migraine is a chronic brain disease that leads to periodic neurological attacks. Parishin A and isorhynchophylline (PI) is the active monomer component extracted from the traditional antimigraine Chinese medicinal combination of Gastrodia and Uncaria, respectively. In this study, using high-performance liquid chromatography coupled with tandem mass spectrometry (HPLC-MS/ MS) technology, we performed pharmacokinetic and lipidomic study on migraine model rats after administration of PI. For the detection of the compounds in plasma, $\mathrm{AB}$ Sciex Triple Quad ${ }^{\mathrm{TM}} 4500$ was applied for quantitative analysis, and the COSMOSIL $\mathrm{C}_{18}$ column $(2.1 \times 100 \mathrm{~mm}, 2.6 \mu \mathrm{m})$ was used for separation. Isorhynchophylline (ISO: $\mathrm{m} / z$ 384.8-241.2) and its main metabolite rhynchophylline (RHY: $m / z$ 384.8-160.2) were simultaneously detected under positive ion modes. Besides, parishin A (PA: $m / z$ 995.1-726.9) and its main metabolite gastrodin (GAS: $m / z$ 331.1-123.0) were simultaneously detected with negative ion modes. For the analysis of endogenous lipid components, Dionex Ultimate 3000 (UHPLC) Thermo Orbitrap Elite was applied for the detection, and the Waters UPLCRBEH C ${ }_{18}$ column $(1.7 \mu \mathrm{m} 100 * 2.1 \mathrm{~mm})$ was used for separation. Chloroform/methanol $(2: 1$, $v: v)$ was used for extraction. The results demonstrated that PI exists significant difference in metabolism between single- and coadministration and can regulate lipid levels associated with migraine.
\end{abstract}

\section{Introduction}

Migraine causes severe head pain and other disabling neurological symptoms, approximately $14.7 \%$ of the global population suffer from migraines, and curative therapies are limited [1,2]. Although western medicines had achieved certain therapeutic effects, high recurrence rates, toxic side effects, and relatively high costs limit their effectiveness in China $[3,4]$. The use of traditional Chinese medicine for the treatment of migraines has been intensely explored. Traditional Chinese medicines provide systemic regulation, have limited side effects, and have multiple targets that minimize drug resistance $[5,6]$.

Gastrodia-Uncaria (known as Tian Ma and Gou Teng in Chinese) is a commonly used medicinal combination for the treatment of vascular migraines and liver-yang-hyperactivity migraines $[7,8]$. In our previous studies, PA and ISO were identified as the major active chemical constituents of Gastrodia and Uncaria and can be absorbed into blood [9]. Besides, further pharmacodynamic assessment of the combination of PA and ISO revealed their antimigraine properties. Because PA and ISO are monomeric components derived from traditional Chinese medicine, the in vivo studies of PI will lay a foundation for the formation of a new antimigraine drug with high efficiency, low toxicity, and controllability.

However, the metabolic process of PA and ISO remains unclear, and the advantages of the combination of PI have not been clarified; besides, the efficacy in animal migraine models has not been clarified. Whilst the pathology of migraines remains largely incomplete, a close relationship to lipid metabolism has been demonstrated as altered lipid levels are frequently reported in migraine patients [10-14]. 
Pharmacokinetic studies provide important references for drug safety and efficacy [15]. Preexperimental data showed that both PA and ISO are unstable in rats and are readily converted to GAS and RHY, respectively. In this study, we employed pharmacokinetic and lipidomic methods to characterize the in vivo mechanism of PI from the perspective of drug metabolism and endogenous lipid regulation. Negative ion modes were employed to assess PA and GAS, whilst positive ion modes were used for the assessment of ISO and RHY. Lipidomics were employed to systematically analyze lipid metabolism under PI treatment conditions [16-18].

\section{Material and Methods}

2.1. Reference Substance and Chemical Reagents. PA (98\%, purity) was purchased from the Purify Technology Development Co., Ltd., Chengdu, China; GAS (98\%, purity) was acquired from the Herbpurify Co., Ltd., Chengdu, China; ISO (98.5\%, purity) was purchased from the Herbpurify Co., Ltd., Chengdu, China; RHY (98\%, purity) was obtained from the Herbpurify Co., Ltd., Chengdu, China; pioglitazone (98\%, purity) was supplied by Herbpurify Co., Ltd., Chengdu, China; geniposide ( $97.6 \%$, purity) was provided by the National Institutes for Food and Drug Control (Beijing, China); plasma was purchased from YiQi Biotechnology Co., Ltd., Henan, China; formic acid, ammonium formate, and isopropanol were purchased from Sigma-Aldrich (St. Louis, MO, USA); methanol, acetonitrile, and formic acid were of chromatographic purity (Fisher, USA).

2.2. Animal Handling. Healthy Sprague-Dawley (SD) female rats weighing $180 \mathrm{~g} \pm 20$ were provided by Hunan SJA Laboratory Animal Co., Ltd. (animal license number: SCXK (Xiang) 2016-0002). Rats underwent adaptive feeding for one week and were fasted for $12 \mathrm{~h}$. Rats had open access to water throughout the study. For pharmacokinetic analysis, $18 \mathrm{SD}$ rats were randomly divided into 3 groups and $0.4 \mathrm{~mL}$ of nitroglycerin (dosage: $10 \mathrm{mg} / \mathrm{kg}$ ) was injected into the forehead to establish the migraine model [19]. After $1 \mathrm{~h}$, rats were intragastrically administered PA alone $(372.4 \mathrm{mg} / \mathrm{kg})$, ISO alone (40 mg/kg), and PI coadministered (ISO: $40 \mathrm{mg}$ / $\mathrm{kg}$, PA: $372.4 \mathrm{mg} / \mathrm{kg}$ ). For blood sampling, $0.3 \mathrm{~mL}$ of blood was taken from the rat orbit prior to drug administration and $0,5,15,30$, and $45 \mathrm{~min}$ and $1,2,4,6,8,10,12$, and $24 \mathrm{~h}$ after administration. These blood samples were collected into EP tubes coated with heparin sodium. After centrifugation at $4000 \mathrm{rmp}$ for $10 \mathrm{~min}$, supernatants were collected and stored at $-80^{\circ} \mathrm{C}$.

For lipidomics, $24 \mathrm{SD}$ rats were randomly divided into three groups: (1) control; (2) model; and (3) administration groups. For the drug-administration groups, $0.4 \mathrm{~mL}$ of nitroglycerin was injected into the rat foreheads, and $1 \mathrm{~h}$ later, rats were intragastrically administered PI (ISO: $40 \mathrm{mg} / \mathrm{kg}$, PA: $372.4 \mathrm{mg} / \mathrm{kg}$ ). Blood was collected from the rat eyelids $1 \mathrm{~h}$ and $24 \mathrm{~h}$ after administration. The collected blood samples were centrifuged at $4000 \mathrm{rmp}$ for $10 \mathrm{~min}$, and supernatants were stored at $-80^{\circ} \mathrm{C}$.
2.3. Preparation of Calibration Standards and Quality Control Samples. For the biological analysis method of simultaneously detecting ISO and RHY, the concentrations of the standard curve was prepared by gradient dilution of the $1 \mathrm{mg} / \mathrm{mL}$ mixed storage solution with appropriate amount of acetonitrile solution, followed by adding blank plasma and IS solution to the final concentration of $0.5,2,10,25,50,100$, and $200 \mathrm{ng} / \mathrm{mL}$. The QC samples included LLOQ $(0.5 \mathrm{ng} /$ $\mathrm{mL})$, LOQ (1 ng/mL), MQC (15 ng/mL), and HQC (150 ng/ $\mathrm{mL}$ ); for detecting PA and GAS, the final concentrations (5, $10,50,100,500,1000$, and $2000 \mathrm{ng} / \mathrm{mL}$ ) of the standard curve were prepared by gradient dilution of the $1.2 \mathrm{mg} / \mathrm{mL}$ mixed storage solution with appropriate methanol solution, followed by adding blank plasma and IS solution. The QC samples included LLOQ (5 ng/mL), LOQ (15 ng/mL), MQC (150 ng/mL), and HQC (1500 ng/mL).

For lipidomics, QC samples were prepared by mixing $10 \mu \mathrm{L}$ of each sample, using PC (17:0) at a concentration of $30 \mu \mathrm{g} / \mathrm{mL}$ as the IS.

2.4. Sample Processing. For pharmacokinetic studies on RHY and ISO, $50 \mu \mathrm{L}$ of plasma was transferred into $1.5 \mathrm{~mL}$ EP tubes to which $50 \mu \mathrm{L}$ of pioglitazone hydrochloride (IS: $175 \mathrm{ng} / \mathrm{mL}$ ) and $250 \mu \mathrm{L}$ of acetonitrile were added. The mixture was vortexed for $3 \mathrm{~min}$ and centrifuged for $10 \mathrm{~min}$ at $13000 \mathrm{rpm} .200 \mu \mathrm{L}$ of supernatants was collected for LC/MS analysis. For GAS and PA assessments, $50 \mu \mathrm{L}$ of geniposide (IS: $350 \mathrm{ng} / \mathrm{mL}$ ) and $250 \mu \mathrm{L}$ of methanol were added to $50 \mu \mathrm{L}$ of the plasma sample. The mixture was vortexed for $3 \mathrm{~min}$ and centrifuged for $10 \mathrm{~min}$ at $13000 \mathrm{rpm}$. $200 \mu \mathrm{L}$ of supernatants was collected into centrifuge tubes, dried in nitrogen, and dissolved in $200 \mu \mathrm{L}$ of $5 \%$ acetonitrile solution (95: $5, v: v)$.

For lipidomic assessment, $100 \mu \mathrm{L}$ of serum was accurately absorbed and $300 \mu \mathrm{L}$ of chloroform/methanol $(2: 1$, $v: v$, containing IS) was added to each sample. Samples were vortexed for $5 \mathrm{~min}$ and subjected to ultrasound for $10 \mathrm{~min}$. Then, the samples were centrifuged at $12000 \mathrm{rpm}$ at $4^{\circ} \mathrm{C}$ for $10 \mathrm{~min}$. Supernatants were collected and precipitates were extracted in $2 \mathrm{~mL}$ of chloroform/methanol $(2: 1, v: v)$ twice. All supernatants were dried in nitrogen and dissolved in chloroform/methanol $(2: 1, v: v) .200 \mu \mathrm{L}$ of supernatants was transferred to sample vials for detection.

2.5. Detection Conditions of LC-MS. For pharmacokinetic studies, the AB Sciex Triple Quad ${ }^{\mathrm{TM}} 4500$ was used for detection. For RHY and ISO chromatographic conditions, the COSMOSIL $\mathrm{C}_{18}$ column $(2.1 \times 100 \mathrm{~mm}, 2.6 \mu \mathrm{m})$ was used at a controlled temperature of $40^{\circ} \mathrm{C}$; phase A consisted of $0.1 \%$ aqueous formic acid (containing $2.5 \mathrm{mM}$ ammonium acetate), and phase B was acetonitrile. A flow rate of $0.5 \mathrm{~mL} / \mathrm{min}$ was used with an injection volume of $2 \mu \mathrm{L}$. The gradient elution was $0.0-1.2 \mathrm{~min}, 5 \% \mathrm{~B} ; 1.2-6.0 \mathrm{~min}, 5-35 \% \mathrm{~B}$; 6.0-8.5 min, 35-95\% B; 8.5-9.0 $\mathrm{min}, 5 \% \mathrm{~B}$; and 9.0-10.0 min, $5 \% \mathrm{~B}$. Under mass spectrometry conditions, the ESI positive ion mode with multiple reaction monitoring (MRM) was used for detection using the following parameters: ion source temperature $=550^{\circ} \mathrm{C}$; ion spray voltage $=4500 \mathrm{~V}$; 
curtain gas $($ nitrogen $)=25$ psi; atomizing gas $($ GS 1$)=50$ psi; auxiliary gas (GS 2$)=50$ psi. Ion pairs were as follows: RHY, $\mathrm{m} / z$ 384.8-160.2 (DP: $122 \mathrm{~V}$; CE: $40 \mathrm{eV}$ ); ISO, $\mathrm{m} / z$ 384.8-241.2 (DP: 122 V; CE $40 \mathrm{~V}$ ). The IS was pyrrolidone hydrochloride, $m / z$ 357.1-134.1 (DP: $85 \mathrm{~V}$; CE: $35 \mathrm{eV}$ ). For GAS and PA, the column temperature was controlled at $40^{\circ} \mathrm{C}$; phase $\mathrm{A}$ was $0.1 \%$ aqueous formic acid, and phase $\mathrm{B}$ was acetonitrile; flow rate was $0.5 \mathrm{~mL} / \mathrm{min}$; injection volume was $2 \mu \mathrm{L}$. The gradient elution was as follows: $0.0-1.2 \mathrm{~min}$, $5 \% \mathrm{~B} ; 1.2-8.0 \mathrm{~min}, \quad 5-95 \% \mathrm{~B} ; 8.0-9.0 \mathrm{~min}, 95-5 \% \mathrm{~B}$; 9.0-10.0 min, 5\% B; $9.0-10.0 \mathrm{~min}, 5 \%$ B. For mass spectrometry, the ESI negative ion mode with MRM mode detection was employed. Mass spectrometry parameters were as follows: ion source temperature $=550^{\circ} \mathrm{C}$; ion spray voltage $=-4500 \mathrm{~V}$; curtain gas $($ nitrogen $)=25$ psi; atomizing gas $(\mathrm{GS} 1)=50$ psi; auxiliary gas $(\mathrm{GS} 2)=50$ psi. Ion pairs were as follows: GAS, $m / z$ 331.1-123.0 (DP: $-60 \mathrm{~V}$; CE: $-20 \mathrm{~V}$ ); PA, $m / z$ 995.1-726.9 (DP: $-165 \mathrm{~V}$; CE: $-39 \mathrm{~V})$. The IS was geniposide, $m / z$ 433.0-225 (DP: $-165 \mathrm{~V}$; CE: $-20 \mathrm{eV}$ ).

For lipidomics, the Dionex Ultimate 3000 (UHPLC) Thermo Orbitrap Elite was used for LC-MS analysis. The following chromatographic conditions were employed: chromatographic column, Waters UPLCRBEH C ${ }_{18}(1.7 \mu \mathrm{m}$ $100 * 2.1 \mathrm{~mm}$ ); mobile phase A, aqueous solution with $0.1 \%$ formic acid (containing $0.1 \% 1 \mathrm{mmol} / \mathrm{L} \mathrm{NH} \mathrm{NH}_{4} \mathrm{COOH}$ ); $\mathrm{B}$, acetonitrile-isopropanol $(1: 1, v: v)$ solution containing $0.1 \%$ $1 \mathrm{mmol} / \mathrm{L} \mathrm{NH}_{4} \mathrm{COOH}$ and $0.1 \% \mathrm{HCOOH}$; flow rate, $0.40 \mathrm{~m} \mathrm{~L} / \mathrm{min}$; column temperature, $45^{\circ} \mathrm{C}$; injection volume, $4 \mu \mathrm{L}$. The optimized gradient elution conditions were as follows: $0-2 \mathrm{~min}, 35-80 \% \mathrm{~B}$; 2-9 $\mathrm{min}, 80-100 \% \mathrm{~B}$; 9-16 min, $100 \% \mathrm{~B} ; 16-20 \mathrm{~min}, 100-35 \% \mathrm{~B}$. The post time was set as $3 \mathrm{~min}$ to balance the system. Mass spectrometry was employed in both positive and negative ion modes. $\mathrm{Pa}$ rameters were optimized as follows in the positive mode: heater temp, $300^{\circ} \mathrm{C}$; sheath gas flow rate, 45 arb; aux gas flow rate, 15 arb; sweep gas flow rate, 1 arb; spray voltage, $3.0 \mathrm{kV}$; capillary temp, $350^{\circ} \mathrm{C}$; S-lens RF level, $30 \%$; mass range, $\mathrm{m} / z$ 200-1500. In the negative mode, the parameters were as follows: heater temperature, $300^{\circ} \mathrm{C}$; sheath gas flow rate, 45 arb; aux gas flow rate, 15 arb; sweep gas flow rate, 1 arb; spray voltage, $2.5 \mathrm{kV}$; capillary temp, $350^{\circ} \mathrm{C}$; S-lens RF level, $60 \%$; mass range, $m / z$ 200-1500.

\subsection{Validation Criteria of Bioanalytical Method.} Validation of the pharmacokinetic method was according to the FDA guidelines, including selectivity, linearity, precision, accuracy, matrix effects, extraction recovery, and stability [20].

For the selectivity, the signal-to-noise ratio of the analyte was at least 10 . For the linear relationship, the correlation coefficient of the standard curves for each compound was greater than 0.99. For inter- and intraday accuracy (RE) and precision (RSD) of QC, the samples did not exceed $15 \%$ and the LLOQ did not exceed $20 \%$. The RSD of mean extraction recoveries, matrix effect, and stability should did not exceed $15 \%$.

2.7. Data Analysis. DAS 3.2.8 software was used to analyze the plasma concentrations in the different groups across all experimental time points [21]. Time-concentration curves were drawn using Sigma Plot 10.0. For lipidomics, raw data were converted to the common (mzData) format using Agilent MassHunter Qualitative Analysis B.08.00 software (Agilent Technologies, USA). In the R software platform, the XCMS program was used to assess peak identification times, retention time correction, and automatic integration pretreatments [22]. Data were subjected to IS and weight normalization. Visualization matrices containing the sample name, $m / z$-RT pair, and peak area were obtained. After removing the ions with a signal-to-noise ratio greater than 500 , the ions with the missing values greater than $80 \%$ in each group, and the internal and isotopic ions, a total of 1654 features were acquired in the positive mode and 1194 were obtained in the negative mode. After editing, data matrices were imported into SIMCA-P 13.0 (Umetrics, Umea, Sweden), mean-centered, and scaled to Pareto variance. Multivariate analysis was then conducted. Combining the data in positive and negative ion modes, an overview was created using unsupervised principal component analysis (PCA) and a DModX was applied to remove outliers. Supervised orthogonal partial least squares-discriminant analysis (OPLS-DA) was applied to distinguish the contribution of the detected variables to the discrimination between model and control groups [23]. The $R 2$ and $Q 2$ values were applied to assess the model. Desirable conditions were obtained when the $R 2$ was close to 1 . Similarly, a $Q 2$ value larger than 0.5 indicated good predictability. In addition, the OPLS-DA models were validated by CV-ANOVA. Metabolic pathways were enriched on the MetaboAnalyst website (http://www.metabo-analyst.ca/). IBM SPSS statistics 21 software was used and two-tailed independent Student's $t$ tests were performed to identify markers with a VIP greater than 1. Filtered metabolites (VIP $>1$ and $P<0.05$ ) were identified as potential biomarkers and matched with the HMDB (http://www.hmdb.ca/), METLIN (https://isometlin. scripps.edu/), MassBank (http://www.massbank.jp/), and ChemSpider (http://www.chemspider.com/). The receiveroperating characteristic (ROC) curve was applied to judge the potential biomarkers in which important biomarkers of migraines had AUC values greater than 0.7 [18].

\section{Results and Discussion}

3.1. Optimization of LC-MS/MS Conditions. RHY and ISO are isomers and so different ion pairs were selected to facilitate both the integration and calculation of the sample peak areas. Liquid chromatography conditions were optimized to meet the baseline separation requirements. As both are alkaloids, favorable intensities for mass spectrometry and improved peak conditions were obtained on the $\mathrm{C}_{18}$ column. The addition of $0.1 \%$ formic acid in the aqueous phase improved the symmetry of the peaks. Acetonitrile promoted sample separation and reduced the column pressure, protecting the ultra high-pressure pumps. Formic acid (0.1\%) and acetonitrile were thus used as the mobile phases.

PA and GAS have different structures, so appropriate IS was required. GEN has similar physical, chemical, and structural properties and was selected as the IS. GAS has a relatively large polarity and short peak time, meaning that it 
was necessary to select a suitable chromatographic column and prolong the analysis time. During sample processing, the double peaks of GAS were eliminated using 5\% acetonitrile water $(5: 95 / v: v)$ to redissolve the GAS and PA. Under acidic conditions, GAS easily formed additive ions with $\mathrm{HCOO}^{-}$. When formic acid was used as the mobile phase, 331.1-123.0 was selected for ion pair detection.

Figure S1 shows the representative multiple reaction monitoring (MRM) chromatograms of the determined compounds at 15 minutes after coadministration in migraine model rats. And Figure S2 displays the representative total ion chromatogram (TIC) of plasma samples in positive and negative ion modes. Both of them show the good results of conditional optimization.

3.2. Validation of Bioanalytical Method. The standard curve (Figure S3) shows the detected compounds and the chromatogram. The selective study of the method validation indicated good linear relationship and selectivity. Table S1 shows the intra- and interday precision and accuracy of PA, GAS, ISO, and RHY. Table S2 shows the extraction recovery, matrix effect, and stability (including short-term, long-term, and repeated freeze-thaw conditions) of each compound. The results indicated that the intra- and interday accuracy of each compound was between $0.08 \%$ and $7.08 \%$, and the precision ranged from $1.50 \%$ to $8.39 \%$, indicating high accuracy and precision. The extraction recovery was between $86.18 \%$ and $104.12 \%$, and the matrix effect was between $85.82 \%$ and $106.83 \%$, indicating good recovery and no effects of the matrix. The RSD of the stability was between $1.04 \%$ and $11.36 \%$, which satisfied the analytical requirements. Thus, the conditions met the requirements for PI analysis in the rat plasma.

3.3. Pharmacokinetic Study. Figure 1 shows the plasma concentration-time curves following single- and coadministration of each compound. The coadministration of ISO, RHY, and GSA was above those of the single-administration groups, whilst PA was almost undetected in either group. Both PA and ISO are unstable in plasma, PA is easily metabolized to GAS, and ISO is easily converted to RHY, resulting in a larger error in the concentration-time curve of the compounds. Table 1 shows the pharmacokinetic parameters of each compound. Following coadministration, the AUC of ISO was 1.31-fold higher than the administration-alone group, whilst RHY was 1.44-fold higher. In addition, the C-max and T-max of both ISO and RHY were larger than those of the single-administration group, suggesting that coadministration promoted the absorption of ISO and RHY into the blood. The half-life $(t 1 / 2 z)$ of ISO through coadministration was 1.99 -fold higher than the administration-alone group, whilst RHY was 3.46-fold higher. The clearance rate (CL $z / F$ ) of ISO in the administration-alone group was 3.15-fold higher than the coadministration group, whilst RHY was 3.16-fold higher. The mean residence time (MRT) of both groups was higher than those of the single-administration group. This indicated that coadministration prolongs the $t 1 / 2 z$ of ISO and RHY, reduces clearance rates, and increases the average residence time, prolonging drug activity in vivo. GAS is a slowly transforming metabolite of PA in the blood [24]. When the pharmacokinetic parameters of GAS were optimized via coadministration, the AUC was 1.31-fold higher than the single-administration group, whilst the $t 1 / 2 z$ was 2.79 -fold higher and the MRT was 1.84-fold higher. This suggested that coadministration promotes drug efficacy in vivo. To date, traditional Chinese medicinal pharmacokinetic studies have been based on healthy experimental animals, discounting the physiological and pathological changes that occur during disease. The pharmacokinetic analyses of drugs used in the treatment of diabetes, cerebral ischemia, hepatobiliary, intestinal disorders, and kidney disease significantly differ from the normal physiological state [25-28]. The disease process can lead to pathological states that influence the activity of related enzymes. As such, animal disease models provide more credible guidance for clinical drug use and enhance practical significance.

3.4. Multivariate Statistical Analysis. Figure S4 shows a representative total ion chromatogram (TIC) of plasma samples in positive and negative ion modes. Figure 2 shows the multivariate analysis of potential migraine biomarkers. PCA data are shown in Figure 2(a) (the $1 \mathrm{~h}$ group) and Figure 2(c) (the $24 \mathrm{~h}$ group). OPLS-DA results are shown in Figure 2(b) (the $1 \mathrm{~h}$ group) and Figure 2(d) (the $24 \mathrm{~h}$ group). These included the control (green) administration groups at $1 \mathrm{~h}$ and $24 \mathrm{~h}$ (blue) and model groups at $1 \mathrm{~h}$ and $24 \mathrm{~h}$ (red). The PCA figures showed that the QC samples displayed good aggregation which reflected the stability of the LC-MS system. The quality of the sample was thus reliable [29]. The PCA analysis was validated no outliers. To further separate the samples and better reflect the differences between control and model groups, samples were analyzed using the supervised mode OPLS-DA, which possesses an improved clustering effect. The results of OPLS-DA showed that the model group and the control group were divided well from each other. Besides, relevant $R^{2} y$ and $Q^{2} y$ values were applied to evaluate the quality of the OPLS-DA model. In the rat lipid metabolism curves, the $R^{2} y$ was $0.966, R^{2} x$ was 0.861 , and $Q 2$ was 0.897 . In the 24 h group, the $R^{2} y$ was $0.967, R^{2} x$ was 0.867 , and Q2 was 0.889 . These results indicate that the model displayed improved predictive parameters indicating significant differences in metabolism between the migraine and control groups [30].

3.5. Identification of Important Lipid Biomarkers. For the assessment of lipid biomarkers, samples were divided into $1 \mathrm{~h}$ analysis (including the $1 \mathrm{~h}$ control and $1 \mathrm{~h}$ model groups) and $24 \mathrm{~h}$ analysis groups (including the $24 \mathrm{~h}$ control and $24 \mathrm{~h}$ model groups). The OPLS-DA model was established to screen contributing variables. A total of 77 variables with a VIP greater than 1 were observed in the $1 \mathrm{~h}$ analysis group, and 170 were identified in the $24 \mathrm{~h}$ analysis group. The metabolites with a VIP $>1$ and $P<0.05$ were identified as candidates. The accurate mass and its MS/MS fragments of the biomarkers were then identified by matching with the 


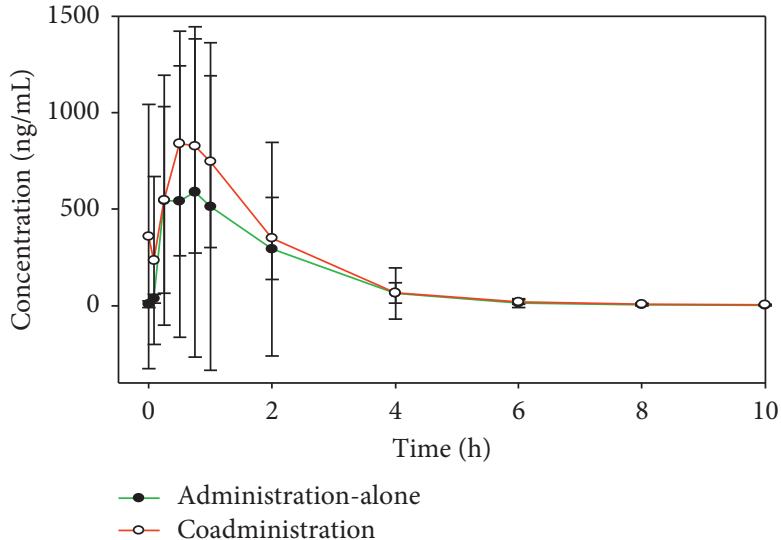

(a)

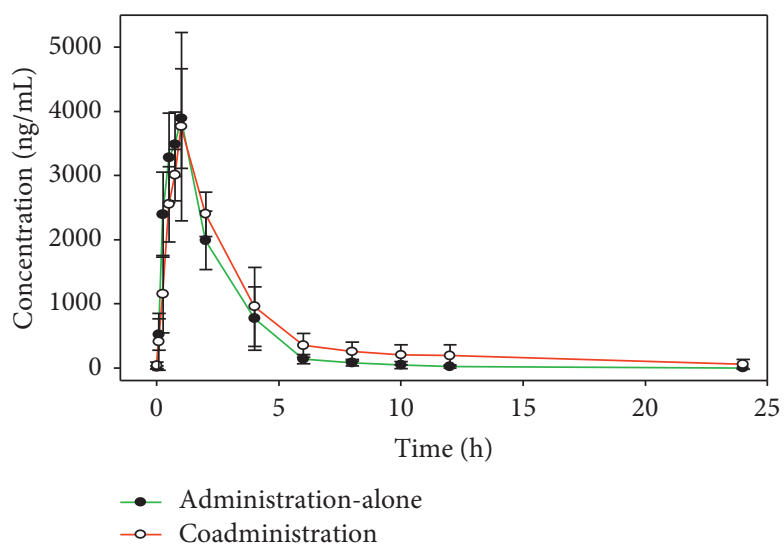

(c)

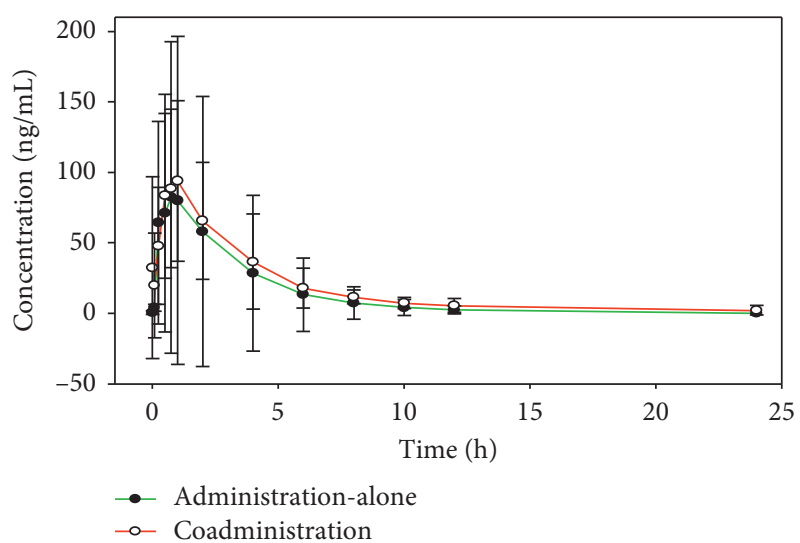

(b)

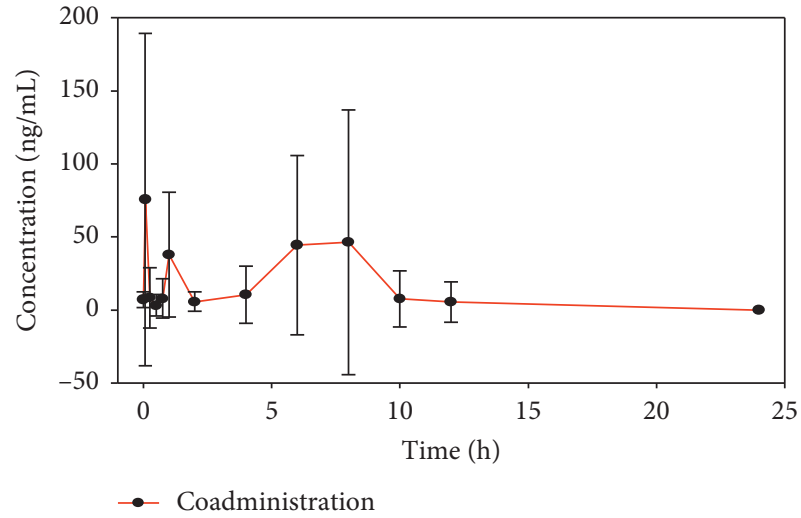

(d)

FIGURE 1: Comparison of plasma concentration-time curves of each compound by administration-alone and coadministration (a) for ISO, (b) for RHY, (c) for GAS, and (d) for PA.

TABle 1: Pharmacokinetic parameters of the determining compounds.

\begin{tabular}{lccccccccc}
\hline \multirow{2}{*}{ Parameters } & \multirow{2}{*}{ Unit } & \multicolumn{2}{c}{ ISO } & \multicolumn{2}{c}{ RHY } & \multicolumn{2}{c}{ GAS } & \multicolumn{2}{c}{ PA } \\
& & Single & Combine & Single & Combine & Single & Combine & Single & Combine \\
\hline AUC $(0-t)$ & $\mu \mathrm{g} / \mathrm{L} * \mathrm{~h}$ & 1340.01 & 1755.85 & 313.95 & 412.82 & 9934.28 & 12757.67 & 0.00 & 304.22 \\
AUC $(0-\infty)$ & $\mu \mathrm{g} / \mathrm{L} * \mathrm{~h}$ & 1340.09 & 1768.51 & 314.00 & 455.57 & 9935.51 & 13028.09 & 0.00 & 304.22 \\
MRT $(0-t)$ & $\mathrm{h}$ & 1.76 & 1.98 & 3.21 & 4.90 & 2.14 & 3.95 & 0.00 & 4.58 \\
MRT $(0-\infty)$ & $\mathrm{h}$ & 1.77 & 2.34 & 3.21 & 8.57 & 2.15 & 4.36 & 0.00 & 4.58 \\
$t 1 / 2 z$ & $\mathrm{~h}$ & 1.90 & 3.79 & 1.63 & 5.64 & 1.02 & 2.85 & 0.00 & 0.69 \\
$\mathrm{~T}-\max$ & $\mathrm{h}$ & 0.54 & 0.58 & 0.63 & 0.96 & 0.83 & 1.08 & 0.00 & 1.99 \\
$V z / F$ & $\mathrm{~L} / \mathrm{kg}$ & 241.72 & 174.09 & 663.02 & 614.92 & 56.61 & 110.10 & 0.00 & 1177.20 \\
$\mathrm{CL} / F$ & $\mathrm{~L} / \mathrm{h} / \mathrm{kg}$ & 88.98 & 28.16 & 331.66 & 104.87 & 38.38 & 29.90 & 0.00 & 8247.98 \\
$\mathrm{C}-\max$ & $\mu \mathrm{g} / \mathrm{L}$ & 645.28 & 867.07 & 88.35 & 94.10 & 4082.17 & 3853.50 & 0.00 & 114.42 \\
\hline
\end{tabular}

online databases such as HMDB (http://www.hmdb.ca/), METLIN (https://isometlin.scripps.edu/), MassBank (http:// www.mass-bank.jp/), and ChemSpider (http://www. chemspider.com/). The error between extraction mass value and experimental mass value was less than $5 \mathrm{ppm}$. During this stage, 44 and 90 potential lipid biomarkers were identified in the $1 \mathrm{~h}$ and $24 \mathrm{~h}$ groups, respectively. To assess the importance of each lipid biomarker, the ROC was assessed. A total of 37 biomarkers were obtained according to the AUC values (Figure 3), 8 of which were in the $1 \mathrm{~h}$ analysis group, 16 were in the $1 \mathrm{~h}$ and $24 \mathrm{~h}$ analysis groups, and 13 were in the $24 \mathrm{~h}$ analysis group. In the model group, the biomarkers (Table 2) in both $1 \mathrm{~h}$ and $24 \mathrm{~h}$ groups were considered important. These included phosphatidylcholines (PCs), lysophosphatides (lysoPC and lysoPE), and sphingolipids (Cer and SM). Box plot analysis (Figure 4) of the 16 biomarkers showed a significantly higher content in the model group compared to the control group, followed by a downward trend following PI administration. 


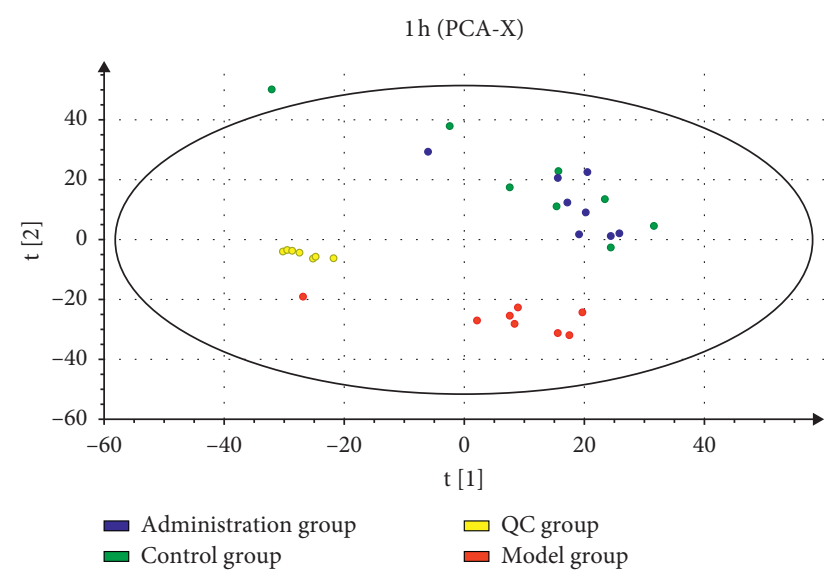

(a)

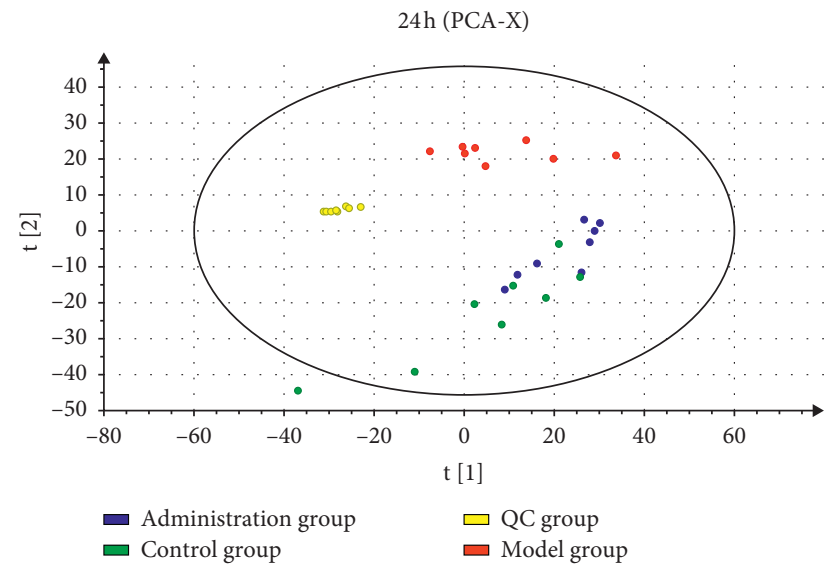

(c)

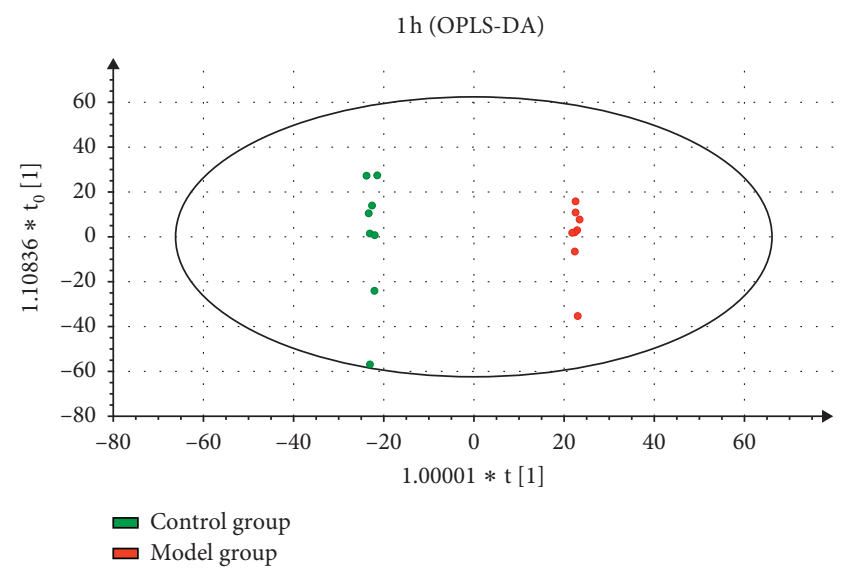

(b)

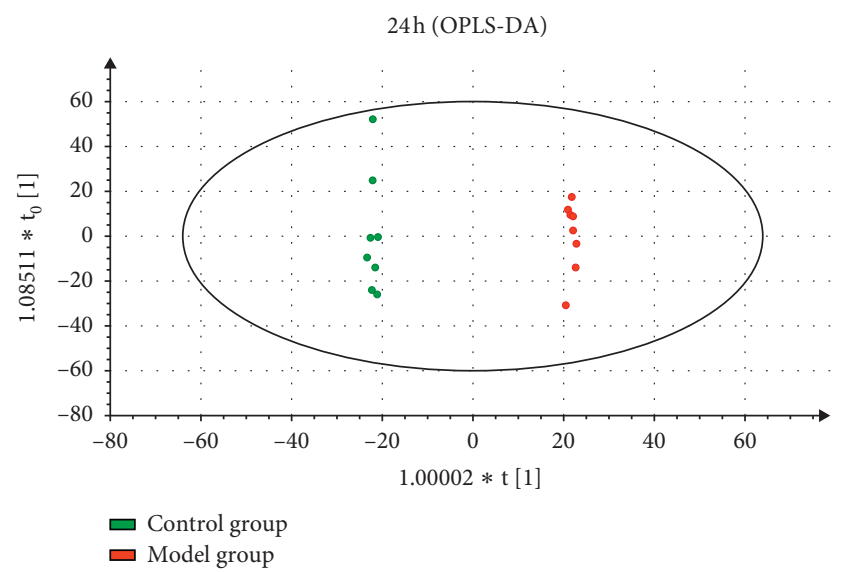

(d)

FIgURe 2: Overview of the sample: (a) PCA score plot in $1 \mathrm{~h}$ after modeling; (b) OPLS-DA score plot in $1 \mathrm{~h}$ after modeling; (c) PCA score plot in $24 \mathrm{~h}$ after modeling; (d) OPLS-DA score plot in $24 \mathrm{~h}$ after modeling.

3.6. Analysis of Metabolic Pathways and Important Lipid Biomarkers. Metabolic pathway analysis is shown in Figure 5. Figure 5(a) provides the metabolic network of migraines of the $1 \mathrm{~h}$ analysis group. These include glycerophospholipid, glycerolipid, and glycosylphosphatidylinositol (GPI)-anchor biosynthesis metabolism. Figure 5(b) shows the metabolic network of migraines of the $24 \mathrm{~h}$ analysis group. These include sphingolipids, linoleic acid, and glycerolipid metabolism. According to the impact value, glycerophospholipid and sphingolipid metabolism were the major pathways of migraine regulation. PC, LPE, and LPC were involved in glycerophospholipid metabolism. In addition, SM and ceramides participated in sphingolipid metabolism. Glycerophosphatidyl is the most abundant type of phospholipids in the body with the basic structures of phosphatidic acid and substituents, which can be divided into phosphatidylcholine, phosphatidylethanolamine, phosphatidylserine, phosphatidylglycerol, phosphatidylinositol, and so on, according to different substituents $[31,32]$. The main function is to form biofilm and participate in protein recognition and signal transduction in cell membranes [33]. Lysophospholipids are produced by the hydrolysis of glycerophospholipids or sphingomyelins to remove one fatty acid side chain [34]. Among which, lysoPC and lysoPE have high abundance and possess important physiological functions and activities [35]. In this study, PC components, LPC (16:0), and LPE (16:0) were identified as important lipid biomarkers of migraine, which involved in the metabolic pathway of glycerophospholipids. Compared with the blank group, the content in migraine model rats increased significantly. PC is the precursor of acetylcholine and can be hydrolyzed into choline in the body [36]. Choline enters the brain along with the blood circulatory system and combines with acetic acid to convert to acetylcholine. Acetylcholine is an important neurotransmitter that promotes communication between brain nerve cells, especially brain neurons $[37,38]$. When the content is increased, the information transmission speed between the brain neurons is accelerated, and the brain nerve function is enhanced. In migraine, promoting the production of PC may regulate the activity of brain tissue. Besides, studies have shown that most migraine sufferers suffer from anxiety and insomnia with or without other stimuli, and these causes of migraine can lead to oxidative stress; when oxidative stress occurs, the production of free radicals activates phospholipase 


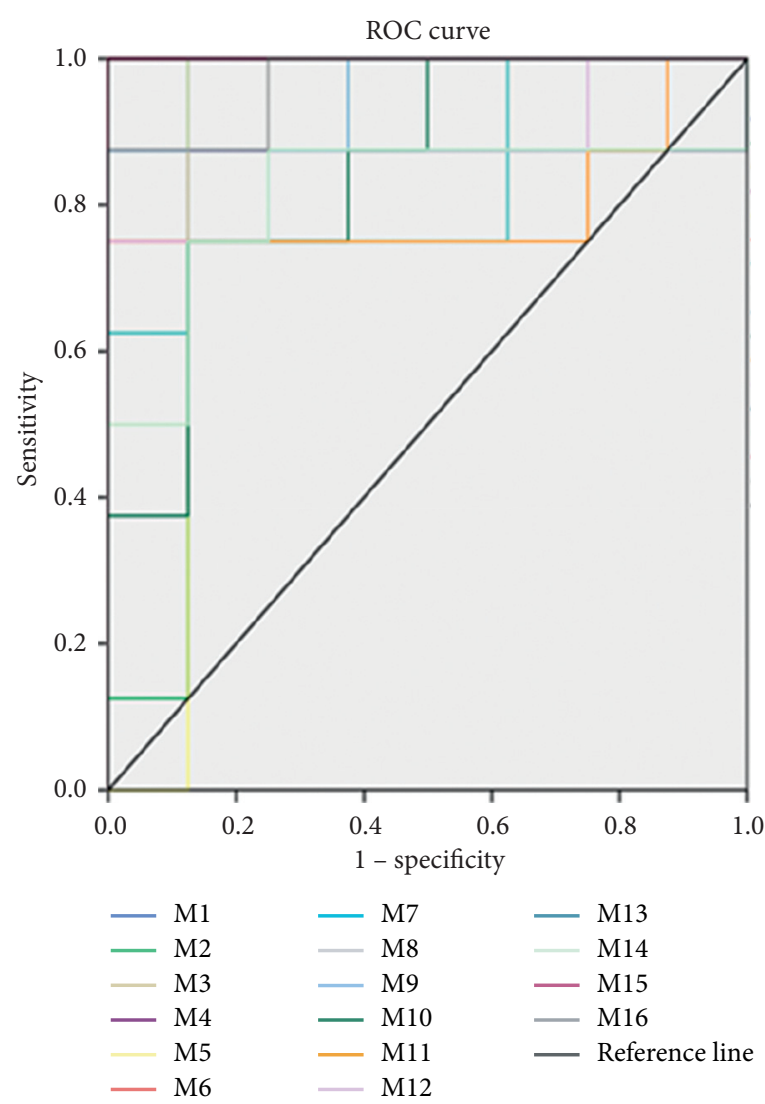

(a)

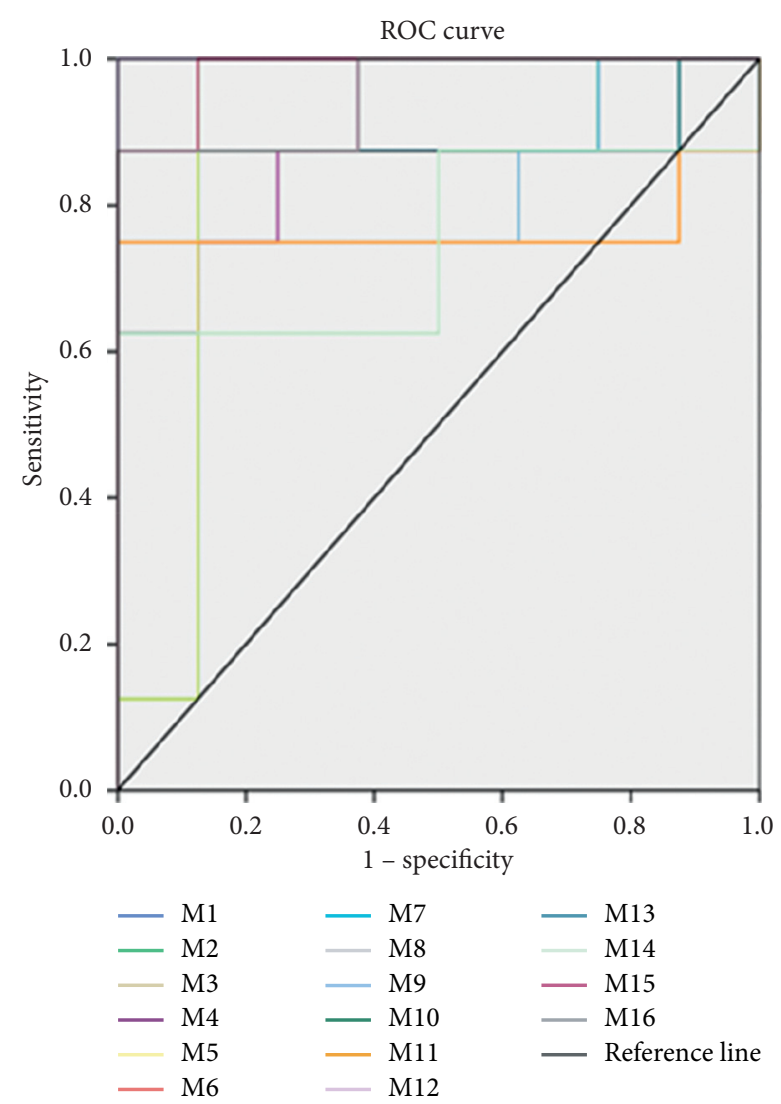

(b)

FIGURE 3: ROC analysis of rat important potential biomarkers: (a) $1 \mathrm{~h}$ group and (b) $24 \mathrm{~h}$ group metabolites.

TABLE 2: Identification of important potential serum lipidomic biomarkers in migraine model rats.

\begin{tabular}{|c|c|c|c|c|c|c|c|c|c|}
\hline No. & Lipid biomarkers & Ion mode & M.F & $\begin{array}{l}\text { Mass } \\
(M / z) \\
\end{array}$ & $\begin{array}{c}\mathrm{Rt} \\
(\mathrm{min})\end{array}$ & $\begin{array}{c}\text { FC (control/model) } \\
1 \mathrm{~h} ; 24 \mathrm{~h} \\
\end{array}$ & $\begin{array}{l}P \text { value } \\
1 \mathrm{~h} ; 24 \mathrm{~h}\end{array}$ & $\begin{array}{c}\text { VIP } \\
1 \mathrm{~h} ; 24 \mathrm{~h} \\
\end{array}$ & $\begin{array}{c}\text { AUC } \\
1 \mathrm{~h} ; 24 \mathrm{~h} \\
\end{array}$ \\
\hline 1 & $\mathrm{PC}(8: 0 e / 10: 0)$ & {$[\mathrm{M}+\mathrm{HCOO}]^{-}$} & $\begin{array}{c}\mathrm{C}_{27} \mathrm{H}_{55} \mathrm{O}_{9} \\
\mathrm{~N}_{1} \mathrm{P}_{1}\end{array}$ & 568.3620 & 4.60 & $0.18 ; 0.11$ & $\begin{array}{c}4.37 E-04 \\
1.12 E-04\end{array}$ & $\begin{array}{c}10.848 \\
9.945\end{array}$ & $\begin{array}{c}0.88 \\
0.88\end{array}$ \\
\hline 2 & $\mathrm{PC}(25: 0 / 9: 0)$ & {$[\mathrm{M}+\mathrm{HCOO}]^{-}$} & $\begin{array}{c}\mathrm{C}_{43} \mathrm{H}_{85} \mathrm{O}_{10} \\
\mathrm{~N}_{1} \mathrm{P}_{1}\end{array}$ & 806.5917 & 13.04 & $0.57 ; 0.59$ & $\begin{array}{c}9.82 E-03 \\
1.51 E-02\end{array}$ & $\begin{array}{l}3.330 \\
2.141\end{array}$ & $\begin{array}{c}0.89 \\
0.81\end{array}$ \\
\hline 3 & PC $(20: 1 / 14: 0)$ & {$[\mathrm{M}+\mathrm{HCOO}]^{-}$} & $\begin{array}{c}\mathrm{C}_{43} \mathrm{H}_{83} \mathrm{O}_{10} \\
\mathrm{~N}_{1} \mathrm{P}_{1}\end{array}$ & 804.5760 & 11.49 & $0.51 ; 0.41$ & $\begin{array}{l}1.96 E-04 \\
2.12 E-02\end{array}$ & $\begin{array}{l}1.937 \\
1.369\end{array}$ & $\begin{array}{l}0.01 \\
1.00 \\
0.78\end{array}$ \\
\hline 4 & PC $(13: 0 / 23: 4)$ & {$[\mathrm{M}+\mathrm{HCOO}]^{-}$} & $\begin{array}{c}\mathrm{C}_{45} \mathrm{H}_{81} \mathrm{O}_{10} \\
\mathrm{~N}_{1} \mathrm{P}_{1}\end{array}$ & 826.5604 & 9.80 & $0.58 ; 0.58$ & $\begin{array}{l}3.34 E-02 \\
2.94 E-03\end{array}$ & $\begin{array}{l}8.614 \\
6.792\end{array}$ & $\begin{array}{c}0.86 \\
0.91\end{array}$ \\
\hline 5 & PC $(17: 0 / 21: 4)$ & {$\left[\mathrm{M}+\mathrm{HCOO}^{-}\right.$} & $\begin{array}{c}\mathrm{C}_{47} \mathrm{H}_{85} \mathrm{O}_{10} \\
\mathrm{~N}_{1} \mathrm{P}_{1}\end{array}$ & 854.5917 & 11.74 & $0.55 ; 0.53$ & $\begin{array}{l}3.20 E-03 \\
4.64 E-03\end{array}$ & $\begin{array}{l}3.534 \\
2.470\end{array}$ & $\begin{array}{l}0.88 \\
0.89\end{array}$ \\
\hline 6 & PC $(21: 4 / 17: 2)$ & {$[\mathrm{M}+\mathrm{HCOO}]^{-}$} & $\begin{array}{c}\mathrm{C}_{47} \mathrm{H}_{81} \mathrm{O}_{10} \\
\mathrm{~N}_{1} \mathrm{P}_{1}\end{array}$ & 850.5604 & 9.34 & $0.15 ; 0.11$ & $\begin{array}{l}2.19 E-06 \\
9.69 E-05\end{array}$ & $\begin{array}{l}8.038 \\
6.412\end{array}$ & $\begin{array}{l}1.00 \\
0.88\end{array}$ \\
\hline 7 & PC $(28: 4 / 12: 0)$ & {$[\mathrm{M}+\mathrm{HCOO}]^{-}$} & $\begin{array}{c}\mathrm{C}_{49} \mathrm{H}_{89} \mathrm{O}_{10} \\
\mathrm{~N}_{1} \mathrm{P}_{1}\end{array}$ & 882.6230 & 12.88 & $0.33 ; 0.15$ & $\begin{array}{l}9.93 E-03 \\
2.53 E-06\end{array}$ & $\begin{array}{l}1.265 \\
1.736\end{array}$ & $\begin{array}{l}0.83 \\
1.00\end{array}$ \\
\hline 8 & PC $(18: 0 / 18: 2)$ & {$[\mathrm{M}+\mathrm{H}]+$} & $\begin{array}{c}\mathrm{C}_{44} \mathrm{H}_{85} \mathrm{O}_{8} \\
\mathrm{~N}_{1} \mathrm{P}_{1}\end{array}$ & 786.6007 & 11.94 & $0.5 ; 0.27$ & $\begin{array}{l}9.35 E-03 \\
9.98 E-05\end{array}$ & $\begin{array}{l}3.445 \\
5.129\end{array}$ & $\begin{array}{l}0.92 \\
1.00\end{array}$ \\
\hline 9 & PC $(18: 0 / 20: 4)$ & {$[\mathrm{M}+\mathrm{H}]+$} & $\begin{array}{c}\mathrm{C}_{46} \mathrm{H}_{85} \mathrm{O}_{8} \\
\mathrm{~N}_{1} \mathrm{P}_{1}\end{array}$ & 810.6007 & 11.77 & $0.62 ; 0.4$ & $\begin{array}{l}2.30 E-02 \\
9.21 E-06\end{array}$ & $\begin{array}{l}2.354 \\
3.620\end{array}$ & $\begin{array}{l}0.84 \\
0.98\end{array}$ \\
\hline 10 & PC $(20: 3 / 20: 3)$ & {$[\mathrm{M}+\mathrm{H}]+$} & $\begin{array}{c}\mathrm{C}_{48} \mathrm{H}_{85} \mathrm{O}_{8} \\
\mathrm{~N}_{1} \mathrm{P}_{1}\end{array}$ & 834.6007 & 11.08 & $0.25 ; 0.13$ & $\begin{array}{l}4.73 E-03 \\
1.11 E-03\end{array}$ & $\begin{array}{l}4.455 \\
5.632\end{array}$ & $\begin{array}{l}0.80 \\
0.77\end{array}$ \\
\hline
\end{tabular}


TABle 2: Continued.

\begin{tabular}{|c|c|c|c|c|c|c|c|c|c|}
\hline No. & Lipid biomarkers & Ion mode & M.F & $\begin{array}{l}\text { Mass } \\
(M / z)\end{array}$ & $\begin{array}{c}\mathrm{Rt} \\
(\mathrm{min})\end{array}$ & $\begin{array}{c}\text { FC (control/model) } \\
1 \mathrm{~h} ; 24 \mathrm{~h}\end{array}$ & $\begin{array}{l}P \text { value } \\
1 \mathrm{~h} ; 24 \mathrm{~h}\end{array}$ & $\begin{array}{c}\text { VIP } \\
1 \mathrm{~h} ; 24 \mathrm{~h}\end{array}$ & $\begin{array}{c}\text { AUC } \\
1 \mathrm{~h} ; 24 \mathrm{~h} \\
\end{array}$ \\
\hline 11 & LPC $(16: 0)$ & {$[\mathrm{M}+\mathrm{H}]+$} & $\begin{array}{c}\mathrm{C}_{24} \mathrm{H}_{51} \mathrm{O}_{7} \\
\mathrm{~N}_{1} \mathrm{P}_{1}\end{array}$ & 496.3398 & 4.02 & $0.39 ; 0.12$ & $\begin{array}{l}4.48 E-03 \\
1.15 E-04\end{array}$ & $\begin{array}{l}1.101 \\
2.053\end{array}$ & $\begin{array}{l}0.88 \\
1.00\end{array}$ \\
\hline 12 & LPE $(16: 0)$ & {$[\mathrm{M}-\mathrm{H}]^{-}$} & $\begin{array}{c}\mathrm{C}_{23} \mathrm{H}_{47} \mathrm{O}_{7} \\
\mathrm{~N}_{1} \mathrm{P}_{1}\end{array}$ & 480.3096 & 2.98 & $0.64 ; 0.55$ & $\begin{array}{l}1.43 E-02 \\
2.29 E-03\end{array}$ & $\begin{array}{c}6.555 \\
5.865\end{array}$ & $\begin{array}{l}0.89 \\
0.92\end{array}$ \\
\hline 13 & SM $(\mathrm{d} 25: 0 / 16: 1)$ & {$[\mathrm{M}+\mathrm{HCOO}]^{-}$} & $\begin{array}{c}\mathrm{C}_{47} \mathrm{H}_{94} \mathrm{O}_{8} \\
\mathrm{~N}_{2} \mathrm{P}_{1}\end{array}$ & 845.6753 & 15.50 & $0.36 ; 0.18$ & $\begin{array}{l}2.59 E-02 \\
2.22 E-02\end{array}$ & $\begin{array}{l}1.880 \\
2.112\end{array}$ & $\begin{array}{l}0.81 \\
0.75\end{array}$ \\
\hline 14 & SM $(\mathrm{d} 17: 0 / 24: 2)$ & {$[\mathrm{M}+\mathrm{CH} 3 \mathrm{COO}]^{-}$} & $\begin{array}{c}\mathrm{C}_{48} \mathrm{H}_{94} \mathrm{O}_{8} \\
\mathrm{~N}_{2} \mathrm{P}_{1}\end{array}$ & 813.6844 & 14.42 & $0.03 ; 0.01$ & $\begin{array}{l}2.90 E-04 \\
2.28 E-03\end{array}$ & $\begin{array}{c}2.678 \\
3.152\end{array}$ & $\begin{array}{l}1.00 \\
0.98\end{array}$ \\
\hline 15 & $\mathrm{SM}(\mathrm{d} 16: 0 / 26: 2)$ & {$[\mathrm{M}+\mathrm{H}]^{+}$} & $\begin{array}{c}\mathrm{C}_{47} \mathrm{H}_{94} \mathrm{O}_{6} \\
\mathrm{~N}_{2} \mathrm{P}_{1}\end{array}$ & 857.6753 & 13.97 & $0.03 ; 0.01$ & $\begin{array}{l}1.27 E-02 \\
3.49 E-04\end{array}$ & $\begin{array}{l}1.768 \\
2.711\end{array}$ & $\begin{array}{l}0.97 \\
0.95\end{array}$ \\
\hline 16 & $\begin{array}{c}\text { CerG2 (d13:0/19: } \\
1)\end{array}$ & {$[\mathrm{M}+\mathrm{H}]^{+}$} & $\begin{array}{c}\mathrm{C}_{44} \mathrm{H}_{84} \mathrm{O}_{13} \\
\mathrm{~N}_{1}\end{array}$ & 834.5937 & 11.08 & $0.32 ; 0.18$ & $\begin{array}{l}1.54 E-03 \\
1.98 E-03\end{array}$ & $\begin{array}{l}4.688 \\
5.277\end{array}$ & $\begin{array}{l}0.88 \\
0.77\end{array}$ \\
\hline
\end{tabular}
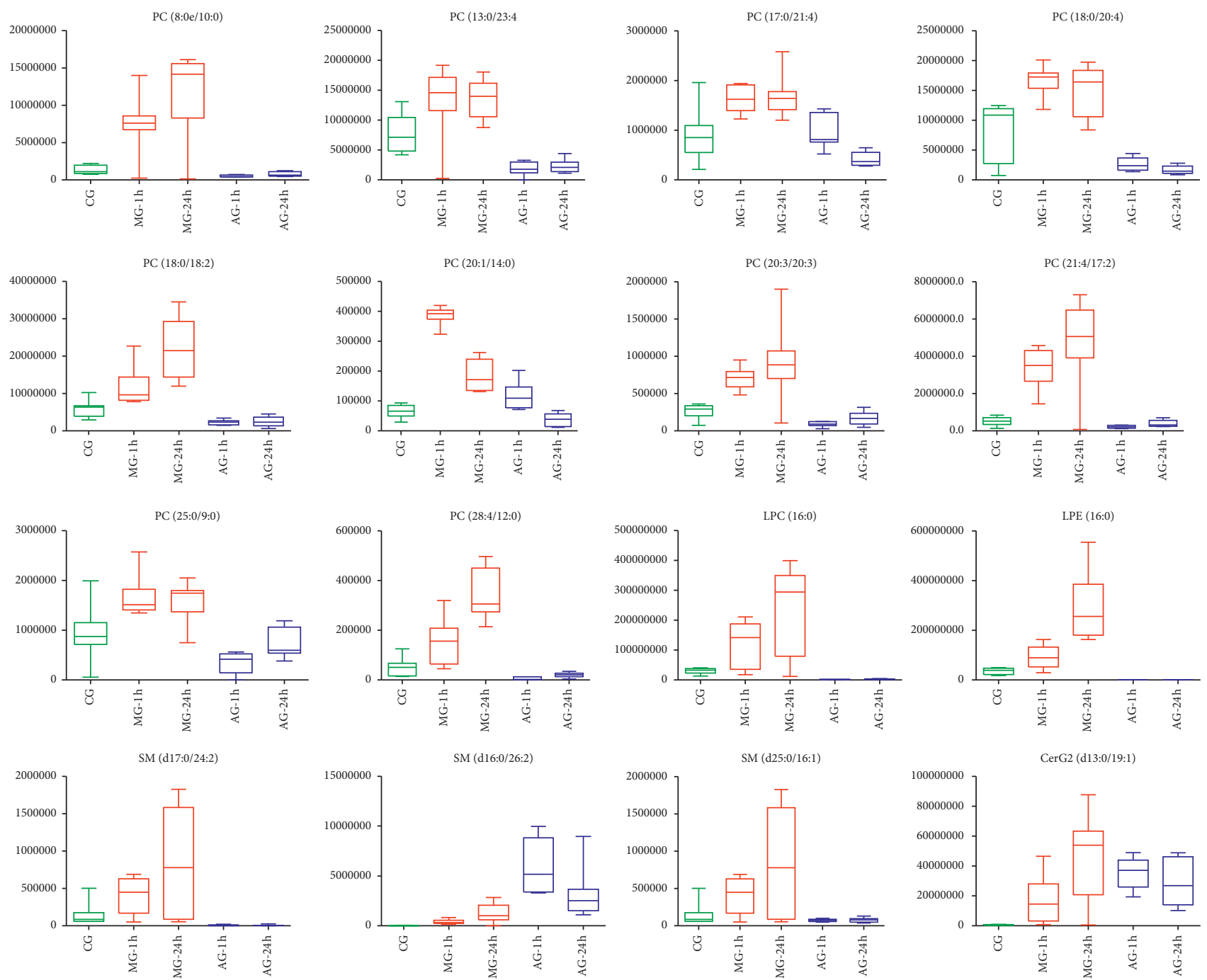

FIgURE 4: Box plot analysis for important lipid biomarkers by the regulation of PI. 


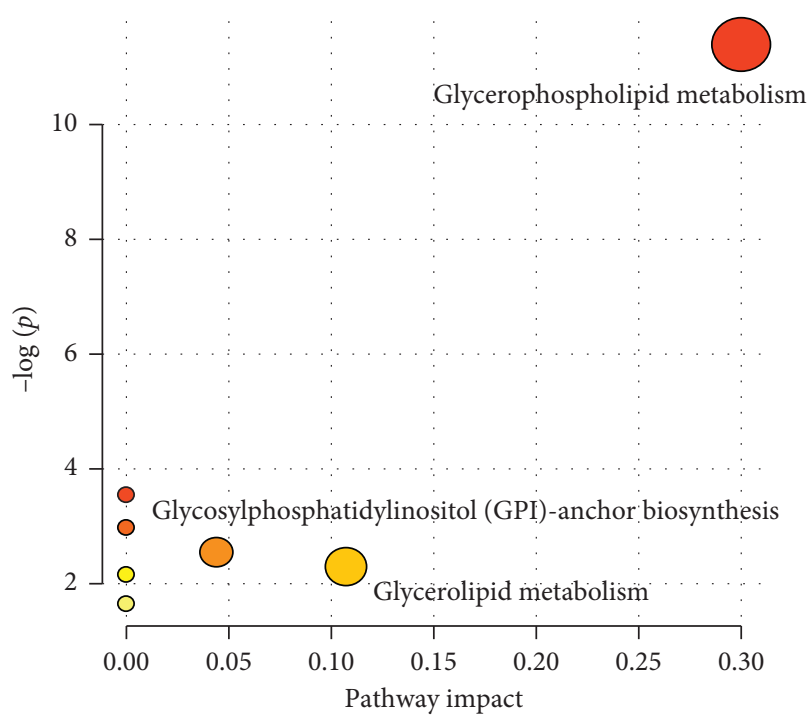

(a)

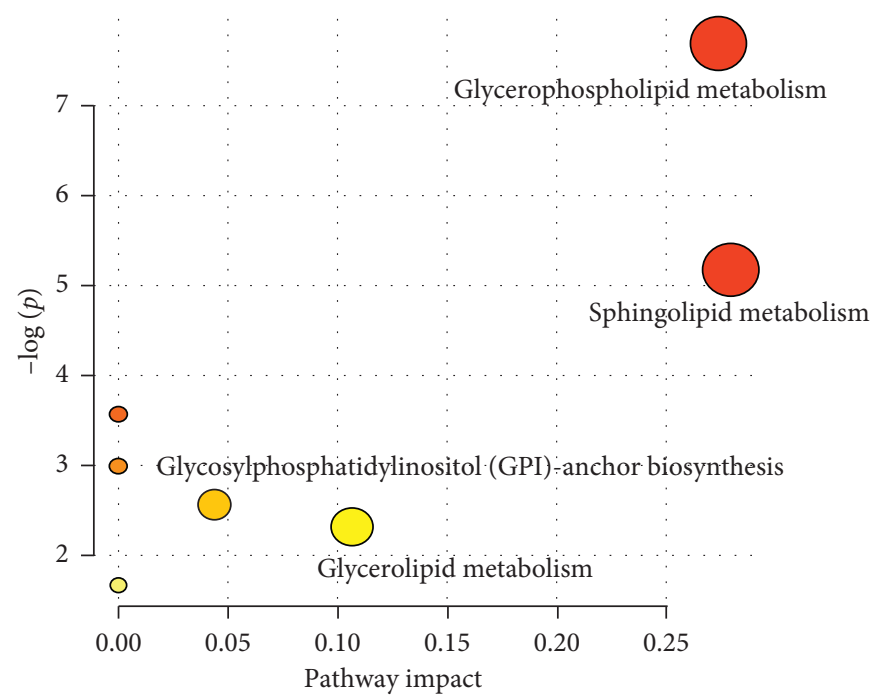

(b)

Figure 5: Metabolic pathway analysis: (a) for $1 \mathrm{~h}$ group and (b) for $24 \mathrm{~h}$ group.

A2 (a biological enzyme that promotes the production of lysophospholipids), thereby increasing the content of lysophospholipids [39-42].

Sphingolipids are the main components of eukaryotic cell membranes, which play an important role in regulating the fluidity of lipid bilayer membranes and in cell signal transduction [43]. Sphingolipids mainly exist in the nervous system, including sphingosine, ceramide (Cer), and sphingomyelin (SM). Human research demonstrated that changes in the balance of sphingolipid metabolism were closely related to neurological diseases [44, 45]. Another basic scientific study suggested that sphingolipids may be involved in pain-related neurological and signaling pathways [46-48]. In this study, we found SM (d17:0/24:2), SM (d16:0/26:2), SM (d25:0/16:1), and CerG2 (d13:0/19:1) were important markers for migraine.

\section{Conclusions}

In this study, the metabolic processes of PI in migraine models were assessed using a combination of pharmacokinetic and lipidomic methods in vivo (endogenous lipid components) and in vitro (PI components). Through comparison of the pharmacokinetic parameters following co- or single-administration, the advantages of coadministration were highlighted. In addition, important lipid biomarkers of migraines were revealed through lipidomic analysis, and the regulatory effects of PI on migraines were confirmed. These studies provide practical reference values for the clinical application of PI.

\section{Abbreviations}

PI: $\quad$ Parishin A and isorhynchophylline

HPLC-MS/ High-performance liquid chromatography

MS: $\quad$ coupled with tandem mass spectrometry

ISO: Isorhynchophylline
RHY: $\quad$ Rhynchophylline

PA: $\quad$ Parishin A

GAS: $\quad$ Gastrodin

MRM: $\quad$ Multiple reaction monitoring

SD: $\quad$ Sprague-Dawley

PCA: $\quad$ Principal component analysis

OPLS-DA: Orthogonal partial least squares-discriminant analysis

ROC: $\quad$ Receiver-operating characteristic

TIC: Total ion chromatogram

CL: $\quad$ Clearance rate

MRT: $\quad$ Mean residence time.

\section{Data Availability}

The data used to support the findings of this study are included within the article.

\section{Conflicts of Interest}

The authors declare that they have no conflicts of interest.

\section{Authors' Contributions}

Chaoqun Zhou and Mingzhen He contributed equally to this work.

\section{Acknowledgments}

The study was funded by a grant (nos. 81660651 and 81560638) from the Natural Science Foundation of China, China Postdoctoral Science Foundation (no. 2017M612159), Jiangxi Postdoctoral Science Foundation (no. 2017KY07), Jiangxi Natural Science Foundation Program (nos. 20171ACB21029 and 20165BCB19009), Jiangxi Health and Family Planning Commission (nos. 2016A009 and 2018A335), Jiangxi Science and Technology Project (no. 
20161BBH80002), Nanchang Innovative Talent Team (Gan Ren She Zi [2018] no. 274), and Project of Jiangxi Education Department (no. GJJ180669).

\section{Supplementary Materials}

Figure S1. Representive MRM chromatograms of the determined compounds at 15 minutes after coadministration in migraine model rats. Figure S2. The representative total ion chromatogram (TIC) of plasma samples in positive and negative ion modes for the pharmacokinetic study. Figure S3. Calibration curves of isorhynchophylline, rhynchophylline, parishin A, and gastrodin in plasma samples. Table S1. Inter- and intraday precision and accuracy for the determination of compounds. Table S2. Extraction recovery, matrix effect, and stability study for the determination of the compounds. (Supplementary Materials)

\section{References}

[1] E. Rogante, S. Sarubbi, D. A. Lamis et al., "Illness perception and job satisfaction in patients suffering from migraine headaches: trait anxiety and depressive symptoms as potential mediators," Headache: The Journal of Head and Face Pain, vol. 59, no. 1, pp. 46-55, 2019.

[2] E. V. Ekusheva, A. R. Artemenko, and V. V. Osipova, "Diagnosis of refractory forms of chronic primary headache," Zhurnal nevrologii i psikhiatrii im. S.S. Korsakova, vol. 117, no. 2, pp. 48-53, 2017.

[3] C.-Y. Wu and C.-Y. Lu, "Derivatization oriented strategy for enhanced detection of valproic acid and its metabolites in human plasma and detection of valproic acid induced reactive oxygen species associated protein modifications by mass spectrometry," Journal of Chromatography A, vol. 1374, pp. 14-22, 2014.

[4] S. Oktay, B. Alev, S. Tunali et al., "Edaravone ameliorates the adverse effects of valproic acid toxicity in small intestine," Human \& Experimental Toxicology, vol. 34, no. 6, pp. 654661, 2015.

[5] P.-H. Wang, L.-X. Zhao, J.-Y. Wan et al., "Pharmacological characterization of a novel gastrodin derivative as a potential anti-migraine agent," Fitoterapia, vol. 109, pp. 52-57, 2016.

[6] C.-S. Shan, Q.-Q. Xu, Y.-H. Shi, Y. Wang, Z.-X. He, and Z. Guo-Qing, "Chuanxiong formulae for migraine: a systematic review and meta-analysis of high-quality randomized controlled trials," Frontiers in Pharmacology, vol. 9, p. 589, 2018.

[7] S. Wang, Y. Chen, D. He et al., "Inhibition of vascular smooth muscle cell proliferation by serum from rats treated orally with Gastrodia and Uncaria decoction, a traditional Chinese formulation," Journal of Ethnopharmacology, vol. 114, no. 3, pp. 458-462, 2007.

[8] S. C. C. Chik, T. C. T. Or, D. Luo, C. L. H. Yang, and A. S. Y. Lau, "Pharmacological effects of active compounds on neurodegenerative disease with gastrodia and uncaria decoction, a commonly used poststroke decoction," The Scientific World Journal, vol. 2013, Article ID 896873, 22 pages, 2013.

[9] X. Zhang, B. Wu, Y. Yao et al., "UHPLC- Q- TOF- MS/MS analysis of migration components in rat blood of tianma Gouteng Yin," Lishizhen Medicine and Materia Medica Research, vol. 9, pp. 33-38, 2017.
[10] A. C. Goulart, P. A. Lotufo, I. S. Santos et al., "The relationship between migraine and lipid sub-fractions among individuals without cardiovascular disease: a cross-sectional evaluation in the Brazilian longitudinal study of adult health (ELSA-Brasil)," Cephalalgia, vol. 38, no. 3, pp. 528-542, 2018.

[11] J. M. Pavlovic, J. R. Vieira, R. B. Lipton, and D. S. Bond, "Association between obesity and migraine in women," Current Pain and Headache Reports, vol. 21, no. 10, p. 41, 2017.

[12] Q. Huang, X. Liang, S. Wang, and X. Mu, "Association between body mass index and migraine: a survey of adult population in China," Behavioural Neurology, vol. 2018, Article ID 6585734, 6 pages, 2018.

[13] B. L. Peterlin, M. M. Mielke, A. M. Dickens et al., "Interictal, circulating sphingolipids in women with episodic migraine: a case-control study," Neurology, vol. 85, no. 14, pp. 1214-1223, 2015.

[14] Z. Wen, H. Mingzhen, C. Peng et al., "Metabolomics and 16S rRNA Gene sequencing analyses of changes in the intestinal flora and biomarkers induced by gastrodia-uncaria treatment in a rat model of chronic migraine," Frontiers in Pharmacology, vol. 10, 2019.

[15] J.-C. Soria, J. Cortes, C. Massard et al., "Phase I safety, pharmacokinetic and pharmacodynamic trial of BMS-599626 (AC480), an oral pan-HER receptor tyrosine kinase inhibitor, in patients with advanced solid tumors," Annals of Oncology, vol. 30, no. 6, p. 1020, 2019.

[16] S. M. Lam and G. Shui, "Lipidomics as a principal tool for advancing biomedical research," Journal of Genetics and Genomics, vol. 40, no. 8, pp. 375-390, 2013.

[17] J. Lv, L. Zhang, F. Yan, and X. Wang, "Clinical lipidomics: a new way to diagnose human diseases," Clinical and Translational Medicine, vol. 7, no. 1, p. 12, 2018.

[18] X. Y. Zhang, J. M. Li, B. Xie et al., "Comparative metabolomics analysis of cervicitis in human patients and a phenol mucilage-induced rat model using liquid chromatography tandem mass spectrometry," Frontiers in Pharmacology, vol. 9, 2018.

[19] Y. Xu, S. Wu, Y. Wu, M. Gong, and Z. Wang, "Recognition and optimization of ingredients treating nitroglycerin-induced migraine rats from Wuzhuyu decoction," EvidenceBased Complementary and Alternative Medicine, vol. 2019, Article ID 6156754, 15 pages, 2019.

[20] Z. Jiang, X. Zheng, and X. Gong, "Relative tissue distribution and excretion studies of gastro-din and parishin from powder and extract of gastrodiae Rhizoma in rat by UHPLC-ESI-MS/ MS," Biomedical Chromatography, vol. 31, no. 7, Article ID e3909, 2017.

[21] Z. Tang, Q. Wang, Z. He, L. Yin, Y. Zhang, and S. Wang, "Liver, blood microdialysate and plasma pharmacokinetics of matrine following transdermal or intravenous administration," Die Pharmazie, vol. 72, no. 3, pp. 167-170, 2017.

[22] Y. Qi, C. Jiang, J. Cheng et al., "Bile acid signaling in lipid metabolism: metabolomic and lipidomic analysis of lipid and bile acid markers linked to anti-obesity and anti-diabetes in mice," Biochimica et Biophysica Acta (BBA)-Molecular and Cell Biology of Lipids, vol. 1851, no. 1, pp. 19-29, 2015.

[23] C. Christou, A. Agapiou, and R. Kokkinofta, "Use of FTIR spectroscopy and chemometrics for the classification of carobs origin," Journal of Advanced Research, vol. 10, pp. 1-8, 2018.

[24] C. Tang, L. Wang, X. Liu, M. Cheng, Y. Qu, and H. Xiao, "Comparative pharmacokinetics of gastrodin in rats after intragastric administration of free gastrodin, parishin and Gastrodia elata extract," Journal of Ethnopharmacology, vol. 176, pp. 49-54, 2015. 
[25] L. Yao, S. Guo, Q. Ren et al., "Pharmacokinetic comparisons of multiple triterpenic acids from extract following oral delivery in normal and acute liver injury rats," International Journal of Molecular Sciences, vol. 19, no. 7, p. 2047, 2018.

[26] T. Yang, S. Liu, C.-H. Wang, Y.-Y. Tao, H. Zhou, and C.-H. Liu, "Comparative pharmacokinetic and tissue distribution profiles of four major bioactive components in normal and hepatic fibrosis rats after oral administration of Fuzheng Huayu recipe," Journal of Pharmaceutical and Biomedical Analysis, vol. 114, pp. 152-158, 2015.

[27] J. Chen, Z. Chen, L. Ma et al., "Development of determination of four analytes of Zhi-Shao-San decoction using LC-MS/MS and its application to comparative pharmacokinetics in normal and irritable bowel syndrome rat plasma," Biomedical Chromatography, vol. 28, no. 10, pp. 1384-1392, 2014.

[28] Y.-H. Wang, Y.-L. Hong, Y. Feng et al., "Comparative pharmacokinetics of senkyunolide I in a rat model of migraine versus normal controls," European Journal of Drug Metabolism and Pharmacokinetics, vol. 37, no. 2, pp. 91-97, 2012.

[29] J. Schlotterbeck, M. Chatterjee, M. Gawaz, and M. Lämmerhofer, "Comprehensive MS/MS profiling by UHPLC-ESI-QTOF-MS/MS using SWATH data-independent acquisition for the study of platelet lipidomes in coronary artery disease," Analytica Chimica Acta, vol. 1046, pp. 1-15, 2019.

[30] R. X. Yang, C. X. Hu, Y. Q. Mi et al., "A serum lipidomic study of patients with non-alcoholic fatty liver disease," Zhonghua Gan Zang Bing Za Zhi, vol. 25, pp. 122-127, 2017.

[31] K. E. Glinton, P. J. Benke, M. A. Lines et al., "Disturbed phospholipid metabolism in serine biosynthesis defects revealed by metabolomic profiling," Molecular Genetics and Metabolism, vol. 123, no. 3, pp. 309-316, 2018.

[32] E. Pittenauer and G. Allmaier, Structural Elucidation of Glycerolipids (TGs, GPLs) by Vacuum MALDI HE-CID TOF/ RTOF Mass Spectrometry, Springer, Dordrecht, Netherlands, 1994.

[33] M. Liscovitch, V. Chalifa, P. Pertile, C. S Chen, and L. C Cantley, "Novel function of phosphatidylinositol 4,5bisphosphate as a cofactor for brain membrane phospholipase D," The Journal of Biological Chemistry, vol. 269, no. 34, pp. 21403-6, 1994.

[34] K. Parchem and A. Bartoszek, "Phospholipids and products of their hydrolysis as dietary preventive factors for civilization diseases," Postepy Higieny I Medycyny Doswiadczalnej (Online), vol. 70, pp. 1343-1361, 2016.

[35] K. Yokoyama, F. Shimizu, and M. Setaka, "Simultaneous separation of lysophospholipids from the total lipid fraction of crude biological samples using two-dimensional thin-layer chromatography," Journal of Lipid Research, vol. 41, no. 1, pp. 142-147, 2000.

[36] H. C. Lee, M. P. Fellenz-Maloney, M. Liscovitch, and J. K. Blusztajn, "Phospholipase D-catalyzed hydrolysis of phosphatidylcholine provides the choline precursor for acetylcholine synthesis in a human neuronal cell line," Proceedings of the National Academy of Sciences, vol. 90, no. 21, pp. 10086-10090, 1993.

[37] G. Leitinger and P. J. Simmons, "Cytochemical evidence that acetylcholine is a neurotransmitter of neurons that make excitatory and inhibitory outputs in the locust ocellar visual system," Journal of Comparative Neurology, vol. 416, no. 3, pp. 345-355, 2015.

[38] L. S. Benardo and D. A. Prince, "Acetylcholine induced modulation of hippocampal pyramidal neurons," Brain Research, vol. 211, no. 1, pp. 227-234, 1981.
[39] S. Geyik, E. Altunisik, AM. Neyal, and S. Taysi, "Oxidative stress and DNA damage in patients with migraine," The Journal of Headache and Pain, vol. 17, no. 1, p. 10, 2016.

[40] D. Tuncel, F. I. Tolun, M. Gokce, S. İmrek, and H. Ekerbiçer, "Oxidative stress in migraine with and without aura," Biological Trace Element Research, vol. 126, no. 1-3, pp. 92-97, 2008.

[41] Y. Eren, E. Dirik, S. Neşelioğlu, and Ö. Erel, "Oxidative stress and decreased thiol level in patients with migraine: crosssectional study," Acta Neurologica Belgica, vol. 115, no. 4, pp. 643-649, 2015.

[42] R. Alp, S. Selek, S. I. Alp, A. Taşkin, and A. Koçyiğit, "Oxidative and antioxidative balance in patients of migraine," European Review for Medical and Pharmacological Sciences, vol. 14, no. 10, pp. 877-882, 2010.

[43] X. L. Guan, C. M. Souza, H. Pichler et al., "Functional interactions between sphingolipids and sterols in biological membranes regulating cell physiology," Molecular Biology of the Cell, vol. 20, no. 7, pp. 2083-2095, 2009.

[44] N. J. Haughey, R. G. Cutler, A. Tamara et al., "Perturbation of sphingolipid metabolism and ceramide production in HIVdementia," Annals of Neurology, vol. 55, no. 2, pp. 257-267, 2004.

[45] D. Wheeler, V. V. R. Bandaru, P. A. Calabresi, A. Nath, and N. J. Haughey, "A defect of sphingolipid metabolism modifies the properties of normal appearing white matter in multiple sclerosis," Brain, vol. 131, no. 11, pp. 3092-3102, 2008.

[46] E. K. Joseph and J. D. Levine, "Caspase signalling in neuropathic and inflammatory pain in the rat," European Journal of Neuroscience, vol. 20, no. 11, pp. 2896-2902, 2004.

[47] K. A. Park and M. R. Vasko, "Lipid mediators of sensitivity in sensory neurons," Trends in Pharmacological Sciences, vol. 26, no. 11, pp. 571-577, 2005.

[48] A. Gnanasekaran, M. Sundukova, A. M. van den Maagdenberg, E. Fabbretti, and A. Nistri, "Lipid raftscontrol P2X3 receptor distribution and function in trigeminal sensory neurons of a transgenic migraine mouse model," Molecular Pain, vol. 7, pp. 1744-8069, 2011. 